\title{
An Introduction to Positive Organizational Scholarship
}

\section{Chapter 1}

in

Cameron, K.S., Dutton, J.E., and Quinn, R.E. (2003)

Positive Organizational Scholarship. (pp. 3-13) San Francisco: Berrett-Koehler. 


\title{
An Introduction to Positive Organizational Scholarship
}

\author{
Kim S. Cameron, Jane E. Dutton, and Robert E. Quinn
}

Imagine a world in which almost all organizations are typified by greed, selfishness, manipulation, secrecy, and a single-minded focus on winning. Wealth creation is the key indicator of success. Imagine that members of such organizations are characterized by distrust, anxiety, self-absorption, fear, burnout, and feelings of abuse. Conflict, law suits, contract breaking, retribution, and disrespect characterize many interactions and social relationships. Imagine also that scholarly researchers investigating these organizations emphasize theories of problem solving, reciprocity and justice, managing uncertainty, overcoming resistance, achieving profitability, and competing successfully against others.

For the sake of contrast, now imagine another world in which almost all organizations are typified by appreciation, collaboration, virtuousness, vitality, and meaningfulness. Creating abundance and human well-being are key indicators of success. Imagine that members of such organizations are characterized by trustworthiness, resilience, wisdom, humility, high levels of positive energy. Social relationships and interactions are characterized by compassion, loyalty, honesty, respect, and forgiveness. Significant attention is given to what makes life worth living. Imagine that scholarly researchers emphasize theories of excellence, transcendence, positive deviance, extraordinary performance, and positive spirals of flourishing.

Positive Organizational Scholarship (POS) does not reject the value and significance of the phenomena of the first world view. Rather, it emphasizes the phenomena represented in the second world view. A focus on competition and profitability in the first world view, for example, is crucial for understanding organizational survival and success. The second world 
view merely calls attention to phenomena that represent positive deviance-phenomena that have received limited scholarly attention in organizational studies. Most organizational theories and empirical research have, heretofore, adopted assumptions and variables that are more typical of the first world view than the second.

\section{The Domain of Positive Organizational Scholarship}

POS is concerned primarily with the study of especially positive outcomes, processes, and attributes of organizations and their members. POS does not represent a single theory, but it focuses on dynamics that are typically described by words such as excellence, thriving,

flourishing, abundance, resilience, or virtuousness. POS represents an expanded perspective that includes instrumental concerns but puts an increased emphasis on ideas of "goodness" and positive human potential. It encompasses attention to the enablers (e.g., processes, capabilities, structures, methods), the motivations (e.g., unselfish, altruistic, contribution without regard to self), and the outcomes or effects (e.g., vitality, meaningfulness, exhilaration, high quality relationships) associated with positive phenomena. POS is distinguished from traditional organizational studies in that it seeks to understand what represents and approaches the best of the human condition. In seeking to understand such phenomena, POS has a number of biases. These biases can be considered in terms of each of the three concepts in the label-Positive Organizational Scholarship.

Positive. POS seeks to understand positive states—such as resilience (see Chapter 7 by Sutcliffe and Vogus) or meaningfulness (see Chapter 20 by Pratt and Ashforth) —as well as the dynamics and outcomes associated with those states—such as gratitude (see Chapter 6 by Emmons) and positive connections (see Chapter 17 by Dutton and Heaphy). This does not mean that traditional organizational studies could be accused of focusing on "negative” or 
undesirable states, only that especially positive states, dynamics, and outcomes usually receive less attention in traditional organizational studies. POS also encompasses the study of systems in equilibrium, but it is especially interested in the nonlinear positive dynamics (what several authors in this volume refer to as "positive spirals," see Chapter 11 by Fredrickson) that are frequently associated with positive organizational phenomena. POS encompasses the examination of typical patterns of behavior and exchange, but it also tends to emphasize the realization of potential, patterns of excellence, especially positive deviance from expected patterns (see Chapter 14 by Spreitzer and Sonenshein). It takes classic questions such as those of organizational leadership and design and uncovers new understanding by examining positive processes that create these patterns (see Chapter 16 by Luthans and Avolio and Chapter 18 by Gittell). Whereas POS does not reject the examination of dysfunctions, or dynamics that disable or produce harm (see Chapter 5 by Weick), it does tend to emphasize the examination of factors that enable positive consequences for individuals, groups, and organizations (see Chapter 12 by Bagozzi). "Positive," in other words, represents an affirmative bias and orientation, not a substitute for other more common organizational phenomena. More often than not, POS focuses on phenomena that are displayed "not in accordance with the situation broadly construed" (see Chapter 3 by Peterson and Park), or, in other words, phenomena that are unexpectedly positive. The interest is in exceptional, virtuous, life-giving, and flourishing phenomena.

Organizational. POS focuses on positive processes and states that occur in association with organizational contexts. It examines positive phenomena within organizations as well as positive organizational contexts themselves. POS draws from the full spectrum of organizational theories to understand, explain, and predict the occurrence, causes, and consequences of positivity. POS expands the boundaries of these theories to make visible positive states, positive 
processes, and positive relationships that are typically ignored within organizational studies. For example, POS spotlights how the virtuousness of organizations is associated with financial performance in the context of downsizing, in contrast to a more typical focus on how organizations try to mitigate the harmful effects of downsizing (see Chapter 4 by Cameron); or, how organizational practices enable individuals to craft meaningful work through fostering individual “callings," in contrast to a more typical focus on employee productivity or morale (see Chapter 19 by Wrzesniewski); or, how the cascading dynamics of empowerment create broader inclusion of stakeholders in public organizations, in contrast to a focus on the political dynamics of stakeholder demands (see Chapter 23 by Feldman and Khademian); or, how building on strengths produces more positive outcomes in a diverse array of settings such as classroom learning, employee commitment, leadership development, and firm profitability, in contrast to a more typical focus on managing or overcoming weaknesses (see Chapter 8 by Clifton and Harter). As this sampling of studies implies, a POS lens exposes new or different mechanisms through which positive organizational dynamics and positive organizational processes produce extraordinarily positive or unexpected outcomes. At the same time, POS purposely illuminates how contexts and processes, and their interactions, are related to positive states in individuals, groups, and organizations.

Scholarship. There is no lack of self-help accounts that prescribe relatively simple and uncomplicated prescriptions for achieving happiness, fulfillment, or effectiveness. What is lacking in most of these contributions, however, is empirical credibility and theoretical explanations for how and why the prescriptions work. Further, these more prescriptive accounts do not speak to the contingencies regarding when the directives will produce the desired results and when they won't. Having a foundation in the scientific method is the basis upon which most 
concepts, relationships, and prescriptions develop staying power. POS does not stand in opposition to the array of self-help publications — many of which recount positive dynamics and outcomes— but it extends beyond them in its desire to develop rigorous, systematic, and theorybased foundations for positive phenomena. POS requires careful definitions of terms, a rationale for prescriptions and recommendations, consistency with scientific procedures in drawing conclusions, and grounding in previous related work. An interest in POS implies a commitment to the full spectrum of activities involved in scholarship. Whereas this book is intended to address an audience of organizational researchers, the success and sustainability of this field requires balanced attention to research, teaching, and practice as three important elements of scholarly endeavor. A bias of POS is to develop theory and research in service of teaching and practice. POS is biased toward appreciating how each of these elements of the scholarly endeavor contributes to the vitality of the others.

\section{Some Correlates of Positive Organizational Scholarship}

An emphasis on positive phenomena is not unique in the social sciences, of course. Other traditions have also examined positive dynamics. In fact, POS has gained particular momentum from literatures in several other fields. Two-positive psychology in Chapter 2 by Peterson and Seligman, and appreciative inquiry in Chapter 15 by Cooperrider and Sekerka—are particularly well described in this volume. Other traditions with a focus on positive phenomena include community psychology, humanistic organizational behavior, organizational development, pro-social motivation and citizenship behavior, and corporate social responsibility.

Positive Psychology. In 1998, the president of the American Psychological Association, Martin Seligman, initiated a new emphasis in the field of psychology, referred to as positive psychology. Seligman argued that since World War II, traditional psychology has focused 
almost exclusively on human pathology, or on what is wrong with and lacking in individuals. This brand of psychology developed the assumption that human beings are inherently fragile and flawed. On the one hand, clinical psychology has made considerable progress in finding strategies of treatment and in moving people from psychological illness toward health. On the other hand, the field has created a deficit bias. It produced a set of theories and practices that described and explained remedies for specific human problems. In contrast, the development of positive psychology was not meant to replace the existing field but to supplement it. Its focus is on strengths and on building the best in life. The basic assumption is that goodness and excellence are not illusions but are authentic states and modes of being that can be analyzed and achieved. Positive psychology has three points of focus: positive experiences such as happiness, pleasure, joy, and fulfillment; positive individual traits such as character, talents, and interests; and positive institutions such as families, schools, business, communities, and societies. This growing literature has begun to capture the attention of both scholars and the media (Snyder \& Lopez, 2002; Seligman, 2002).

Community Psychology. Historically, community psychology has had an emphasis on the prevention of illness and on wellness enhancement. Jahoda's (1958) treatment of positive mental health was one of the first attempts to "express dissatisfaction with a primary focus on sick behavior” (p. ix) and to emphasize prevention of illness and wellness. She identified six domains of prevention based community psychology: positive self-attitudes, wholesome growth and development, personal integration, autonomy, accurate perception of reality, and mastery of one’s environment. Other writers in community psychology, notably Cowen (1967, 1973, 1977, 1980, 1986, 1994, 1999) also discussed principles and practices associated with prevention of mental illness. Community based prevention and wellness enhancement programs have been 
studied and described in that literature, as illustrated by Durlak and Wells’ (1997) summary of 177 studies of prevention and wellness and their positive outcomes. Unfortunately, little dissemination of those findings has occurred in the more general field of psychology or in organizational studies.

Organizational Development and Appreciative Inquiry. Organizational development (OD) was founded on a set of techniques and strategies for changing, developing, and enhancing the functioning of organizations - especially the internal human features of the organization. In OD, a recent movement has emerged that focuses directly on "searching for the best in people, their organizations, and the relevant world around them . . . [it] involves in a central way the art and practice of asking questions that strengthen a system's capacity to apprehend, anticipate, and heighten positive potential” (Cooperrider \& Whitney, 2000:5) Chapter 15 in this volume describes the foundation of this movement—called appreciative inquiry—which has recently received a substantial amount of attention among consultants and change agents (Srivastava \& Cooperrider, 1999; Cooperrider \& Whitney, 2000). Appreciative inquiry refers to a composite of change practices that are based on the assumption that organizations have a positive core which, if revealed and tapped, unleashes positive energy and positive improvement. The change process proceeds by identifying past examples of peak performance, spectacular successes, or positive aspirations for the future. Key explanatory elements are identified which account for these past successes, and a vision of the future is crafted based on what was extraordinarily successful and what can be perpetuated in the future. The success and popularity of this approach to organizational development have advanced at a more rapid pace than the articulation of the theory for why it works, so the scholarly opportunities for POS researchers to examine and comprehend the underlying dynamics of appreciative inquiry are abundant. 
Prosocial and Citizenship Behavior. An increasing amount of attention has also been given to prosocial behavior at work, sometimes called citizenship behavior, which refers to helping behaviors designed to provide assistance or benefit to others (Krebs, 1982; Organ, 1988; George, 1991; Batson, 1994). These types of behaviors exceed role requirements and are pursued in spite of not being associated with a formal organizational reward (Bolino, Turnley, \& Bloodgood, 2002). Examples range from providing assistance to customers or co-workers in a work setting to volunteer or philanthropic activity outside of work. In all cases, prosocial and citizenship behavior refers to voluntary actions that provide benefit to other people. Related literature has appeared on topics such as rescuing Jews in Nazi Europe, fund-raising, assisting starving refugees, saving whales and endangered species, assisting Third World countries, donating organs, enhancing group welfare, and so on (Batson, 1994; Podsakoff, MacKenzie, Paine, \& Bachrach, 2000). An on-going debate in psychology centers on whether or not prosocial behavior is really just a selfish act designed to satisfy a personal, egotistical need, or whether empathy and altruism are the chief motivators of prosocial behavior. A variety of experiments have been performed to test the nature of prosocial motivation (Batson, 1991), but the debate continues.

Corporate Social Responsibility. An increasing literature on corporate social responsibility centers on the obligation of organizations, especially corporations, to address societal problems and ills (Margolis \& Walsh, 2002; Whetten, Rands, \& Godfrey, 2001). All three branches of the United States government have urged corporations to become involved in promoting social welfare- from contributing to the global AIDS fund to establishing minimum wage standards. A large number of non-governmental organizations (NGOs) have also been established to address social problems, and to pressure corporations to join them in taking 
responsibility for addressing human suffering. Various academic disciplines have long been interested in social welfare, social justice, and human rights (e.g., accounting, economics, strategy, and organizational behavior), and most of this scholarly work has focused on the relationship between corporate social performance (i.e., involvement in socially responsible activities) and financial performance. In an extensive review of the literature, Margolis and Walsh (2002) reported that 53 percent of the studies pointed to a positive relationship between corporate social performance and financial performance when the latter was treated as the dependent variable. Two thirds (68 percent) of the studies that treated financial performance as an independent variable found a positive relationship with corporate social performance.

The point of our brief discussion of these related scholarly traditions is to acknowledge that the emphasis on positive phenomena is neither unique nor new. Much scholarly work has been done in other arenas. On the other hand, too little of that work has found its way into organizational studies, and with the exception of positive psychology and appreciative inquiry, much of that work remains focused on overcoming ills, problems, and difficulties rather than on flourishing, on extraordinarily positive dynamics, or on the best of the human condition. POS as a field of study seeks to capitalize on these related scholarly traditions, but POS also represents an extension of what is known to date about generative and life-giving phenomena in organizations.

\section{Advantages of a Positive Organizational Scholarship Perspective}

POS is a fresh lens. It offers new ways of looking at old phenomena. By applying this new lens, elements that were formerly invisible become visible. POS helps people look at phenomena in new ways. For example, POS can help traditional network and social capital research uncover energizing and generative relationships (see Chapter 21 by Cross, Baker and 
Wooten); typical work on adaptation can uncover new patterns of replenishment and resilience (see Chapter 7 by Sutcliffe and Vogus); typical work on information exchange and learning can uncover new pathways for knowledge creation (see Chapter 13 by Lee, Caza, Edmundson and Thomke); typical work on motivation can uncover unexpected and transcendent motivational dynamics (see Chapter 9 by Bateman and Porath); and typical work on problem solving and deficit gaps can uncover abundance gaps (See Chapter 15 by Cooperrider and Sekerka).

To repeat, POS is not value-neutral. It advocates the position that the desire to improve the human condition is universal and that the capacity to do so is latent in most systems. The means by which this latent capacity is unleashed and organized, the extent to which human possibilities are enabled, and the extent to which systems produce extraordinarily positive outcomes are of special interest. POS does not exclude phenomena that are typically labeled positive in organizational studies—such as organizational improvement, goal achievement, or making a profit—but it has a bias toward life-giving, generative, and ennobling human conditions.

In other words, POS seeks to be a generative lens for linking theories in organizational studies. As an example, POS can uncover new sources and forms of capabilities that build on human generative processes. By focusing on the generative dynamics of human organizing, POS provides an expanded view of how organizations can create sustained competitive advantage. By unlocking capacities for elements such as meaning creation, relationship transformation, positive emotion cultivation, and high quality relationships, organizations can produce sustained sources of collective capability that help organizations thrive. POS offers a unique conceptual foundation for understanding how and why organizational strategies have their effects on human 
behavior in the workplace, and why some strategies and dynamic capabilities may be more generative than others.

\section{Outline of the Book}

Our purpose in this volume is to provide groundwork for a new emphasis on positive organizational phenomena. The intent is to make positive phenomena available for systematic and rigorous investigation by organizational scholars. We are mindful of Cowen and Kilmer's (2002) observation that the social sciences are filled with faddish concepts and perspectives that have lost credibility and relevance because people accepted too quickly an alluring concept that was not conceptually defined and rigorously investigated. Such concepts receive short-lived attention, spinning off in disconnected directions and never generating cumulative findings or theories. "Even though there may be good agreement about the pristine beauty and promise of the new concept as an abstraction, people may diverge substantially in how, concretely, its operations are best understood and implemented” (p. 450). The intent of each chapter in this volume is to invite organizational scholars to build upon and extend the positive organizational phenomena being examined. These chapters each provide definitional, theoretical, and/or empirical foundations for what we anticipate will become a cumulative body of enduring work.

We have organized the chapters into three sections. These sections are an arbitrary way to capture some basic themes in POS phenomena. The first section—Virtuous Processes, Strengths, and Positive Organizing — contains chapters on virtues and strengths in individuals and organizations that are associated with positive outcomes. Chapters also discuss extraordinarily positive organizing processes. The second section—Upward Spirals and Positive Change-identifies the generative dynamics associated with self-reinforcing, positive spirals in organizations. The effects of positive emotions, inquiry, and leadership on individuals and 
organizations are examined. The third section—Positive Meanings and Positive Connectionscontains chapters focusing on positive human relationships and the positive meaning of, and in, work that are associated with human flourishing and positive dynamics in organizations. Each of these sections contains chapters that ground a specific concept or phenomenon in scholarly literature, identify its relationship to positive organizational scholarship, and guide further scholarly work with suggested research questions and additional areas of needed study. The chapters are intended to be invitations to further work by providing a foundation upon which scholarship can expand.

In the first section, Peterson and Park (Chapter 3) provide an overview of the extensive work being done to classify strengths and virtues in the field of positive psychology. The chapter focuses specifically on six widely-shared organizational virtues that help produce the good society, the good workplace, and the good school. Chapter 4 by Cameron introduces the concept of organizational virtuousness and examines its relationship to several measures of organizational performance. The results demonstrate that organizations scoring high in virtuousness have higher levels of performance, especially after downsizing. Weick's Chapter 5 examines the dynamics of tragic and traumatic events, and it highlights how a POS perspective helps explain the absence of "a million accidents waiting to happen. Chapter 6 by Emmons introduces the concept of gratitude and identifies the importance of this phenomenon in organizational settings. Research is reviewed that establishes relationships between feelings and expressions of gratitude and desirable individual and organizational outcomes. The chapter by Sutcliffe and Vogus (Chapter 7) highlights resilience as a key attribute of flourishing organizations. They identify predictors, dimensions, contributors, and effects of resilience in organizations, groups, and individuals. Chapter 8 by Clifton and Harter reviews a variety of 
empirical studies that support the proposition that building strengths is the most efficient focus for individual and organizational improvement efforts. The authors point out that individuals and organizations gain more when they build on their strengths than when they make comparable efforts in overcoming weaknesses. Bateman and Porath (Chapter 9) introduce the concept of transcendent motivation. Transcendent behavior is that which surpasses environment or personal constraints and creates positive change in the person or the environment. Conceptual and empirical dimensions of the construct are developed. Chapter 10 by Worline and Quinn focuses on the virtue of courageous principled action in fostering innovation and vitality in the major organizational forms and structures.

The second section focuses on upward spirals, or the dynamics of escalating positive phenomena in organizations. In chapter 11, Fredrickson focuses on positive emotions in organizations. Based on her broaden-and-build-theory, she explains how positive emotions can transform individuals and organizations and move them in upward spirals to higher levels of performance. Bagozzi uses Chapter 12 to focuses on the dynamics of emotions, mapping how such emotions give rise to both negative and positive outcomes in organizations. In Chapter 13, Lee, Caza, Edmondson, and Thomke focus on attributes of organization members and the processes of knowledge creation. They show how knowledge-creating processes give rise to self-reinforcing or upward dynamics. In Chapter 14, Spreitzer and Sonenshein discuss the concept of positive deviance, or the manifestation of extreme positive behaviors in organizations, and they provide a research agenda for further examining the dynamics involved. In Chapter 15, Cooperrider and Sekerka provide a review of the literature on Appreciative Inquiry (AI) and present a new model of AI that explains the understructure of the process for unleashing potential in organizations. Luthans and Avolio craft Chapter 16 by drawing from their respective 
past efforts on leadership. They define what is meant by authentic leadership and offer a theoretically driven model for developing authentic leaders.

The third section contains chapters focusing on relationships, positive connections, and meaningfulness. In Chapter 17 Dutton and Heaphy introduce the concept of high quality connections and develop four mechanisms through which high quality connections enable individuals to thrive. Gittell uses the idea of high quality connections to build a new perspective on the positive dynamics of coordination mechanisms in organizations (Chapter 18). Chapters 19 and 20 focus on the positive meanings created at work and their impact on individuals and organizations. Wrzesniewski focuses on the powerful effects of work orientations referred to as "callings" and how individuals can craft their work to make it more meaningful. Pratt and Ashforth use core concepts of identity to build a theory of how organizational contexts foster meaningfulness both in working and at work. They examine how contexts enrich memberships, tasks and roles. The next chapter introduces ideas of positive energy as means for explaining positive dynamics of connection (Cross, Baker and Wooten). More specifically, Cross, Baker and Wooten (Chapter 21) develop a new perspective they call positive network analysis that explains how the positive energy created in positive ties delivers extraordinary results. They begin to unpack the mechanisms that contribute to these effects. Last, but definitely not least, Feldman and Khademian in Chapter 22 take on the dynamics of inclusion and empowerment in a public management context. Their model of cascading inclusion shows how empowerment on the "inside" of an organization, creates democracy and participation for stakeholders on the “outside”.

Taken as a whole, these chapters represent only a sampling of key POS phenomena, of course, but they do begin to create a foundation upon which additional scholarly work can build. 
Their intent is to provide empirical, theoretical, and logical arguments so that a science of positive organizational dynamics can flourish. 


\section{References}

Batson, C.D. (1994) "Why act for the public good? Four answers.” Personality and Social Psychology Bulletin, 20: 603-610.

Bolino, M.C., Turnley, W.H., and Bloodgood, J.M. (2002) “Citizenship behavior and the creation of social capital in organizations.” Academy of Management Review, 27: 505522.

Cooperrider, D.L. and Whitney, D. (2000) “A positive revolution in change: Appreciative inquiry.” In Cooperrider, D.L., Sorenson, P.F., Whitney, D, and Yeager, T.F. (Eds.) Appreciative inquiry. (pages 3-28). Champaign, IL: Stipes Publishing.

Cowen, E.L. (1977) “Baby steps toward primary prevention. American Journal of Community Psychology, 5: 1-22.

Cowen, E.L. (1980) “The wooing of primary prevention.” American Journal of Community Psychology, 8: 258-284.

Cowen, E.L. (1986) "Primary prevention in mental health: Ten years of retrospect and ten years or prospect.” In Kessler, M. and Goldston, S.E. (Eds.) A decade of progress in primary prevention. (pages 3-45). Hanover, NH: University Press of New England.

Cowen, E.L. (1994) “The enhancement of psychological wellness: Challenges and opportunities.” American Journal of Community Psychology, 22: 149-179.

Cowen, E.L. (1999) “In sickness and in health: Primary prevention’s vows revisited.” In Cicchetti, D., and Toth, S.L. (Eds.) Rochester Symposium on Developmental Psychopathology: Developmental Approaches to Prevention and Intervention. Vol. 10 (pp. 1-24) Rochester: University of Rochester Press. 
Cowen, E.L., Gardner, E.A., and Zax, M. (Eds.) Emergent approaches to mental health problems: An overview and directions for future work. New York: Appleton-Century Crofts.

Cowen, E.L. \& Kilmer, R.P. (2002) “Positive psychology: Some plusses and some open issues.” Journal of Community Psychology, 30: 449-460.

Durlak, J.A. and Wells, A.M. (1997) "primary prevention programs for children and adolescents: A meta-analytic review.” American Journal of Community Psychology, 25: 115-152.

George, J.M. (1991) State or trait: Effects of positive mood on prosocial behaviors at work.” Journal of Applied Psychology, 76: 299-307.

Jahoda, M. (1958) Current Concepts of Positive Mental Health. New York: Basic Books.

Krebs, D.L. (1975) “Empathy and altruism.” Journal of Personality and Social Psychology, 32: 1134-1146.

Margolis, J.D. and Walsh, J.P. (2002) "Misery loves companies.: Whither social initiatives by business?” Working paper, University of Michigan Business School.

Organ, D.W. (1988) Organizational Citizenship Behavior: The Good Soldier Syndrome. Lexington, MA: Lexington Books.

Podsakoff, P.M., MacKenzie, S.B., Paine, J.B., and Bachrach, D.G. (2000) “Organizational citizenship behaviors: A critical review of the theoretical and empirical literature and suggestions for future research.” Journal of Management, 26: 513-563.

Seligman, M.E.P. (2002) Authentic Happiness: Using the New Positive Psychology to Realize Your Potential for Lasting Fulfillment. New York: Free Press.

Snyder, C.R. and Lopez, S.J. (2002) Handbook of Positive Psychology. New York: Oxford University Press. 
Srivastava,S. and Cooperrider, D.L. (1999) Appreciative Management and Leadership: The Power of Positive Thought and Action in Organization. Williams Custom Publishing.

Whetten, D.A., Rands, G., and Godfrey, P. (2001) "What are the responsibilities of business to society?” In Pettigrew, A., Thomas, H., and Whittington, R. (Eds.) Handbook of Strategy and Management. (pp. 373-408). Thousand Oaks: Sage.

Zax, M. and Cowen, E.L. (1976) Abnormal psychology: Changing conceptions. New York: Holt, Rinehart, \& Winston. 


\section{POSITIVE ORGANIZATIONAL SCHOLARSHIP}

Edited by

Kim S. Cameron, Jane E. Dutton, and Robert E. Quinn

San Francisco: Berrett-Koehler Publishers, 2003.

\section{Part One: Introduction}

1 Foundations of Positive Organizational Scholarship

Kim S. Cameron, Jane E. Dutton, and Robert E. Quinn

2 Positive Organizational Studies: Lessons from Positive Psychology Christopher M. Peterson and Martin E.P. Seligman

Part Two: Virtuous Processes, Strengths, and Positive Organizing

3 Virtues and Organizations

Nansook Park and Christopher M. Peterson

4 Organizational Virtuousness and Performance

Kim S. Cameron

5 Positive Organizing and Organizational Tragedy

Karl E. Weick

6 Acts of Gratitude in Organizations

Robert A. Emmons

7 Organizing for Resilience

Kathleen M. Sutcliffe and Timothy J. Vogus

8 Strengths Investment

Donald O. Clifton and James K. Harter

9 Transcendent Behavior

Thomas Bateman and Christine Porath

10 Courageous Principled Action

Monica C. Worline and Ryan W. Quinn

Part Three: Upward Spirals and Positive Change

11 Positive Emotions and Upward Spirals in Organizations Barbara L. Fredrickson

12 Positive and Negative Emotions in Organizations

Richard P. Bagozzi

13 New Knowledge Creation in Organizations

Fiona Lee, Arran Caza, Amy Edmondson, and Stefan Thomke

14 Positive Deviance and Extraordinary Organizing

Gretchen M. Spreitzer and Scott Sonenshein

15 Toward a Theory of Positive Organizational Change

David L. Cooperrider and Leslie E. Sekerka

16 Authentic Leadership and Positive Development

Fred Luthans and Bruce Avolio 
Part Four: Positive Meanings and Positive Community

17 The Power of High Quality Connections

Jane E. Dutton and Emily D. Heaphy

18 A Relational Theory of Coordination

Jody Hoffer Gittell

19 Finding Positive Meaning in Work

Amy Wrzesniewski

20 Fostering Meaningfulness in Working and at Work

Michael G. Pratt and Blake E. Ashforth

21 Positive Organizational Network Analysis and Energizing Relationships

Wayne Baker, Rob Cross and Melissa Wooten

22 Empowerment and Cascading Vitality

Martha S. Feldman and Anne M. Khademian

\section{Part Five: Conclusion}

23 Positive Organizing and the Future of Organizational Scholarship

Kim S. Cameron, Jane E. Dutton, Robert E. Quinn, and Amy Wrzesniewski 